\title{
Comparative Study of Maintenance and Recovery Characteristics of Sevoflurane and Isoflurane in Neurosurgery
}

\author{
Lulu Fatema Vali ${ }^{1}$, Sonali M. Khobragade ${ }^{2}$ \\ ${ }^{1}$ Professor, Department of Anaesthesiology, Government Medical College And Hospital, Nagpur, ${ }^{2}$ Associate Professor, Department of Anaesthesiology, \\ Indira Gandhi Government Medical College And Hospital, Nagpur.
}

\section{Abstract}

Background: Rapid recovery is very important in neurosurgical patients for early neurological assessment. The purpose of this study was to compare the maintenance and recovery characteristics of two most commonly used volatile anaesthetic agents, Isoflurane and Sevoflurane in neurosurgery patients. Subjects and Methods: A hospital based, prospective, randomized, comparative study was undertaken in tertiary care centre for a period of two years after institutional ethical committee approval. The study included 60 patients undergoing neurosurgical surgeries in general anaesthesia. After intravenous induction, maintenance was achieved by inhalational anaesthetic agent according to randomly allocated group. Haemodynamic parameters like heart rate, systolic blood pressure, diastolic blood pressure along with recovery time and complications were studied and $\mathrm{p}<0.05$ was considered significant on statistical analysis. Results: The pulse rate was significantly less in sevoflurane group than isoflurane group from $20 \mathrm{~min}$ to $120 \mathrm{~min}(\mathrm{p}<0.05)$. The mean systolic and diastolic blood pressure were comparable in both the groups except the systolic and diastolic blood pressure were lower in Sevoflurane group than Isoflurane group at $5 \mathrm{~min}(\mathrm{p}<0.05)$. The mean emergence time and extubation time were significantly shorter in Sevoflurane group than Isoflurane group $(\mathrm{p}<0.001)$. Conclusion: Sevoflurane provides stable haemodynamics during maintenance of anaesthesia and allows rapid recovery for faster postoperative basic neurological assessment.

Keywords: Isoflurane, Sevoflurane, Maintenance and Recovery, Neurosurgical patients.

Corresponding Author: Dr. Sonali M. Khobragade, plot No. 238, C/O Dr. M.D. Khobragade, Kukde Lay Out, Nagpur, Maharashtra, India.

Received: June 2019

Accepted: July 2019

\section{Introduction}

The landmark in the history of inhaled anaesthetic agents was in 1846 when Williams Thomas G Morton, for the first time demonstrated the effect of sulphuric ether in public in Massachusetts general hospital, Boston successfully.

After 1846, with Morton as the hero of this invention, ether was brought into the daily lives of surgeons. Surgery, which was agony before this event, became more or less painless for the patients and easy for surgeon. The evolution of modern volatile anaesthetic agents has been detected by increasing concern for the safety and ease of use. The prediction in 1932 of the ideal properties of current fluorinated inhalational agents is a reminder of the substantial recent progress in the era 1970-1990. Nitrous oxide, of course, was another anaesthetic agent being used at the same time. It was demonstrated first in 1846 in Boston after which it was considered a failure. In 1868, nitrous oxide was reintroduced in United States by Colton. Thus inhalational anaesthetic agents started their journey from the dentists' chamber with the ether and nitrous oxide and now have reached a stage where newer drugs are being discovered with newer ways of effective delivery in modern operation theatres with newer sophisticated anaesthesia machines and standardized vaporizers. There have been many advances in the development of new inhalational agents in the last four decades. Inhalational agents remain the commonest agents for maintenance of anaesthesia. The new inhalational agents discovered allow a rapid, pleasant induction and stable hemodynamics and rapid recovery with minimal hangover effect. Isoflurane1 was the 469 compound made by Ross Terell in 1965 and his associates in their search for better inhaled anaesthetic. Isoflurane is a colourless, clear, stable liquid, has a mildly pungent, musty, etheral odour. Initial work in animal led to human studies, which indicated that isoflurane might possess superior attributes. Further studies in animal and volunteers and clinical testing in 3,000 patients, confirmed these initial impressions. ${ }^{[1]}$ Sevoflurane is newly introduced fluorinated ether inhaled anaesthetic agent, ${ }^{[2]}$ first synthesized by Bernard W. Regan in 1968. It has desirable properties of low gas partition coefficient and non-pungent character. It was first given to human volunteers in 1981 and has been in clinical practise since 1990. Sevoflurane despite some excellent anaesthetic characteristic, there was concern regarding possible neurotoxicity from fluoride ion toxicity and Compound a formation. These were the primary reasons for the slow development of Sevoflurane outside Japan. FDA approved the use of Sevoflurane in June 1995 with the caution that it 
not be used at fresh gas flows of less than 2 litres per min. Sevoflurane have been widely investigated in animal studies and humans. ${ }^{[3-5]}$ These investigations suggest that sevoflurane maintains anaesthesia safely without disturbances of the cardiovascular system and its low solubility provide more rapid emergence from anaesthesia than is possible with the existing volatile anaesthetics. Haemodynamics should be stable and variations should be minimal when neurosurgery is concerned. For a long time isoflurane was considered to be the agent of choice of inhalational anaesthetic agent in neuroanaesthesia. Moreover in Neurosurgery cases, early recovery is critical to obtain for early neurological assessment in the postoperative period. Schwender et al(1998), ${ }^{[6]}$ had shown Sevoflurane has several characteristics of an ideal neuroanaesthetic agent. Cardiovascular variables were well maintained with Sevoflurane. Edward Frink et al (1992), ${ }^{[7]}$ showed that systemic systolic and diastolic arterial blood pressures were not significantly different from those occurring in the Isoflurane anaesthesia. However, there are limited published reports, which compare Sevoflurane and Isoflurane anaesthesia in neurosurgery in respect to maintenance and recovery characteristics. Hence a prospective, randomized study was planned and carried out.

\section{Subjects and Methods}

This prospective, randomized study was conducted at the tertiary care hospital after approval from institutional ethics committee. Sixty patients undergoing major elective neurosurgical procedures were included in the study.

\section{Inclusion Criteria}

Patients of ASA grade I and II, Either sex, Age 18-50 years, Duration of surgery around 3 hours.

\section{Exclusion Criteria}

Head injury patients, Diabetic patients, Hypertensive patients, Patients with impaired cardiac, pulmonary, hepatic, renal function.

Sixty patients satisfying inclusion criteria were studied. Patients were randomly divided into two groups of 30 each using random number table.

Group I: Patients for general anaesthesia maintained on Isoflurane.

Group S: Patients for general anaesthesia maintained on Sevoflurane.

Detailed preoperative evaluation of the patients with history, complete general and systemic examination including neurological examination was carried out clinically. Patients age, sex, weight, haemoglobin, urine exam were noted and kidney function tests, liver function tests, ECG, CT/MRI scan, chest X-ray were noted. Patients satisfying inclusion criteria were included in the study after taking valid informed consent. All patients were kept nil by mouth for 8 hours and received tab. Lorazepam $2 \mathrm{mg}$ and tab. Ranitidine $150 \mathrm{mg}$ at the bed time. Patient's baseline pulse rate and blood pressure was recorded after attaching monitor to the patient. A peripheral intravenous access was taken with $18 \mathrm{G}$ cannula and radial artery cannulation was done under local anaesthesia. Patients were premedicated with Inj. Glycopyrrolate $5 \mathrm{mcg} / \mathrm{kg}$, Inj. Dexamethasone $8 \mathrm{mg}$, Inj. Midazolam $0.04 \mathrm{mg} / \mathrm{kg}$ and Inj. fentanyl $1 \mathrm{mcg} / \mathrm{kg}$. Patients were pre-oxygenated with $100 \%$ oxygen for $3-5 \mathrm{~min}$. Anaesthesia was induced with Inj.Thiopentone sodium $2.5 \%$ $5 \mathrm{mg} / \mathrm{kg}$ slow and Inj. Vecuronium $0.1 \mathrm{mg} / \mathrm{kg}$. After induction and complete neuromuscular blockade, patients were intubated with proper size cuff endotracheal tube. Anaesthesia was maintained

In GROUP I: with $50 \%$ nitrous oxide and $50 \%$ oxygen with Isoflurane (1-1.5\%) and I.V. Vecuronium (maintenance dose $0.02 \mathrm{mg} / \mathrm{kg})$.

In GROUP S: with $50 \%$ nitrous oxide and $50 \%$ oxygen with Sevoflurane (2-3\%) and I.V. Vecuronium (maintenance dose $0.02 \mathrm{mg} / \mathrm{kg}$ ).

Intermittent positive pressure ventilation was given with respiratory rate of $16-20 \mathrm{breaths} / \mathrm{min}$ with tidal volume 8 $10 \mathrm{ml} / \mathrm{kg}$ using closed circuit to maintain ETCO2 between $30-35 \mathrm{mmHg}$. Sevoflurane or Isoflurane concentrations were adjusted throughout surgical procedure to maintain minimal fluctuations of arterial blood pressure $(+20 \%)$ in response to surgical stimulation. Inj. Mannitol was given to all the patients in the dose of $0.5 \mathrm{mg} / \mathrm{kg}$ after skin incision and before opening of duramater.

Blood pressure and pulse rate were continuously monitored and recorded at $1,5,10,20,30,60,120$ and $180 \mathrm{~min}$ after induction. SPO2 and ETCO2 were monitored continuously. Fluids were given according to the anaesthesia requirement and intraoperative blood loss. Towards the end of the procedure last top up dose of vecuronium avoided. At the end of the surgical procedure, inhalational agent and nitrous oxide were switched off simultaneously and time was noted. Patients were reversed as soon as his spontaneous respiratory efforts appeared. Patients were extubated as soon as the reflexes were regained. Time was noted from switching off inhalational agents to opening of eyes by patients on verbal command without noxious stimulation.

\section{Extubation of endotracheal tube}

Patient telling correct name on asking, after extubation.

Postoperatively patients were monitored for incidences of coughing, salivary secretions, vomiting, nausea and shivering for one hour. Blood pressure and pulse rate and adequacy of spontaneous respiration were observed.

Defining intra-operative complications and its management. Hypotension - MAP $<30 \%$ of basal, MAP is considered significant. Treated by fluid challenge, Inj. Mephentermine $6 \mathrm{mg}$, decreasing concentration of inhalational agent, inotropic agent in severe and resistant cases.

Hypertension - MAP> $30 \%$ of basal is considered significant, treated by increasing Isoflurane concentration (MAXIMUM up to $1.5 \%$ ) or Sevoflurane (max upto $3 \%$ ), Inj. Fentanyl 20mcg, vasodialators (NTG) in severe and resistant cases.

Bradycardia - HR $<50$ BPM considered significant and treated as Inj. Atropine $0.3 \mathrm{mg}$ in incremental doses. HR $<60 B P M$ if associated with hypotension considered as significant and treated as Inj. Atropine $0.3 \mathrm{mg}$ incremental doses.

Tachycardia - HR> 100BPM is considered significant and treated as fluid challenge, Inj. Fentanyl $20 \mathrm{mcg}$. 
0

Statistical analysis: data was collected tabulated, coded and then analysed using SPSS computer software version 20.0. Numerical values expressed as mean $+/$ - standard deviation. Demographic data were analysed by unpaired student " $\mathrm{t}$ " test.

Gender comparison was done by chi-square test.

Cardiovascular data were compared with student t' test.

$\mathrm{P}<0.05$ was considered significant. $\mathrm{P}<0.001$ was considered highly significant.

\section{Results}

60 patients enrolled in the study with comparable demographic characteristics such as age, sex, weight and duration of surgery.

Table 1: Changes in Mean Heart Rate after Administration of Isoflurane

\begin{tabular}{|l|l|l|l|}
\hline HR at & Mean SD & \% Change IN HR & Significance \\
\hline PREOP & $75.03 \pm 7.483$ & 0 & - \\
\hline 1 MIN & $82.77 \pm 9.16$ & 10.31 & 0.001 \\
\hline 5 MIN & $79.17 \pm 8.26$ & 5.51 & 0.04 \\
\hline 10 MIN & $78.93 \pm 6.50$ & 5.20 & 0.032 \\
\hline 20 MIN & $80.83 \pm 7.47$ & 7.73 & 0.004 \\
\hline 30 MIN & $80.73 \pm 7.73$ & 7.60 & 0.005 \\
\hline 60 MIN & $80.13 \pm 6.53$ & 6.80 & 0.007 \\
\hline 120 MIN & $80.07 \pm 6.63$ & 6.71 & 0.008 \\
\hline 180 MIN & $87.85 \pm 10.37$ & 17.08 & 0.001 \\
\hline
\end{tabular}

There was significant increase in pulse rate after Isoflurane administration throughout the study period. The increase was less than $20 \%$ requiring any intervention.

Table 2: Changes in Mean Heart Rate after Administration of Sevoflurane

\begin{tabular}{|l|l|l|l|}
\hline HR at & Mean SD & \% Change IN HR & Significance \\
\hline PREOP & $78.40 \pm 8.15$ & 0 & - \\
\hline 1 MIN & $81.97 \pm 9.27$ & 4.55 & 0.12 \\
\hline $5 \mathrm{MIN}$ & $77.57 \pm 8.60$ & -1.06 & 0.70 \\
\hline $10 \mathrm{MIN}$ & $77.53 \pm 7.83$ & -1.11 & 0.68 \\
\hline $20 \mathrm{MIN}$ & $76.86 \pm 7.53$ & -1.96 & 0.45 \\
\hline $30 \mathrm{MIN}$ & $76.27 \pm 7.87$ & -2.72 & 0.31 \\
\hline $60 \mathrm{MIN}$ & $76.06 \pm 7.68$ & -2.98 & 0.26 \\
\hline $120 \mathrm{MIN}$ & $75.83 \pm 7.23$ & -3.27 & 0.20 \\
\hline $180 \mathrm{MIN}$ & $82.21 \pm 8.71$ & 4.87 & 0.16 \\
\hline
\end{tabular}

There was no significant change in pulse rate from baseline in the study period after Sevoflurane administration.

\section{CHANGES IN MEAN HEART RATE}

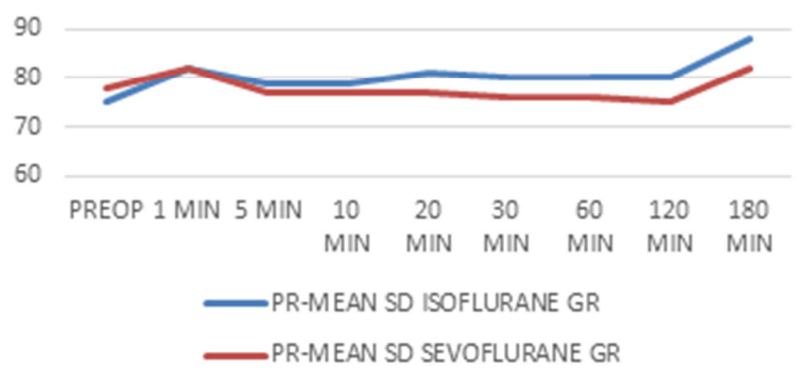

Figure 1: Changes in Mean Heart Rate after Administration of Isoflurane and Sevoflurane
On intergroup comparison, the pulse rate was statistically significantly lower in Sevoflurane group than Isoflurane group from 20 minutes till 120 minutes.

Table 3: Changes in Mean Systolic Blood Pressure after Administration of Isoflurane

\begin{tabular}{|l|l|l|l|}
\hline SBP at & Mean SD & \%Change IN SBP & Significance \\
\hline PREOP & $123.60 \pm 10.12$ & 0 & - \\
\hline 1 MIN & $137 \pm 9.26$ & 10.84 & $0.001(\mathrm{HS})$ \\
\hline 5 MIN & $129.53 \pm 0.28$ & 4.80 & $0.03($ S) \\
\hline 10 MIN & $119.53 \pm 6.92$ & -3.29 & 0.07 \\
\hline 20 MIN & $119.20 \pm 9.20$ & -3.56 & 0.08 \\
\hline 30 MIN & $118.90 \pm 9.84$ & -3.80 & 0.07 \\
\hline 60 MIN & $118.67 \pm 9.70$ & -3.99 & 0.06 \\
\hline 120 MIN & $118.83 \pm 8.92$ & -3.86 & 0.06 \\
\hline 180 MIN & $124.31 \pm 7.25$ & 0.57 & 0.82 \\
\hline
\end{tabular}

There was significant increase in SBP at $1 \mathrm{~min}$ and $5 \mathrm{~min}$ in Isoflurane group. Thereafter, there was no significant change in SBP from baseline in the study period.

Table 4: Changes in Mean Systolic Blood Pressure after Administration of Sevoflurane

\begin{tabular}{|l|l|l|l|}
\hline SBP at & Mean SD & \%Change IN SBP & Significance \\
\hline PREOP & $121.53 \pm 8.15$ & 0 & - \\
\hline 1 MIN & $132.73 \pm 7.96$ & 9.2 & $0.001(\mathrm{HS})$ \\
\hline 5 MIN & $124.13 \pm 7.24$ & 2.1 & 0.20 \\
\hline 10 MIN & $122.63 \pm 8.35$ & 0.9 & 0.61 \\
\hline 20 MIN & $122.07 \pm 7.17$ & 0.4 & 0.79 \\
\hline 30 MIN & $119.60 \pm 6.59$ & -1.6 & 0.32 \\
\hline 60 MIN & $120.23 \pm 7.62$ & -1.1 & 0.53 \\
\hline 120 MIN & $119.90 \pm 7.83$ & -1.3 & 0.43 \\
\hline 180 MIN & $120.77 \pm 6.53$ & -0.6 & 0.07 \\
\hline
\end{tabular}

There was significant increase in SBP at $1 \mathrm{~min}$ in Sevoflurane group. Thereafter, there was no significant change in SBP from baseline in the study period.

\section{CHANGES IN MEAN SBP}

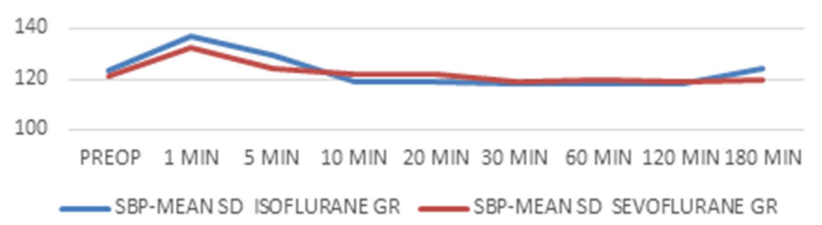

Figure 2: Changes in mean systolic blood pressure after administration of isoflurane and sevoflurane

On intergroup comparison, there was no statistically significant difference in SBP in the study period of 180 minutes except the SBP in Sevoflurane group was significantly lower than Isoflurane group at 5 minutes.

Table 5: Changes In Mean Diastolic Blood Pressure After
Administration Of Isoflurane
\begin{tabular}{|l|l|l|l|}
\hline DBP at & MEAN SD & \%Change IN DBP & Significance \\
\hline PREOP & $75.73 \pm 5.32$ & 0.00 & - \\
\hline 1 MIN & $83.73 \pm 5.66$ & 10.57 & $0.01($ S) \\
\hline 5 MIN & $80.40 \pm 5.30$ & 6.17 & $0.01(\mathrm{~S})$ \\
\hline 10 MIN & $74.87 \pm 5.08$ & -1.14 & 0.52 \\
\hline 20 MIN & $73.63 \pm 4.59$ & -2.77 & 0.11 \\
\hline 30 MIN & $73.43 \pm 4.68$ & -3.03 & 0.08 \\
\hline 60 MIN & $74.63 \pm 4.86$ & -1.45 & 0.41 \\
\hline 120 MIN & $74.60 \pm 5.37$ & -1.49 & 0.42 \\
\hline 180 MIN & $77.08 \pm 4.59$ & 1.78 & 0.43 \\
\hline
\end{tabular}


There was significant increase in DBP at $1 \mathrm{~min}$ and $5 \mathrm{~min}$ in Isoflurane group. Thereafter, there was no significant change in SBP from baseline in the study period.

Table 6: Changes in Mean Diastolic Blood Pressure after
Administration of Sevoflurane
\begin{tabular}{|l|l|l|l|}
\hline DBP at & Mean SD & \% Change IN DBP & Significance \\
\hline PREOP & $75.50 \pm 4.75$ & 0 & - \\
\hline $1 \mathrm{MIN}$ & $81 \pm 5.71$ & 7.28 & $0.001(\mathrm{HS})$ \\
\hline $5 \mathrm{MIN}$ & $76.50 \pm 5.66$ & 1.32 & 0.46 \\
\hline $10 \mathrm{MIN}$ & $73.57 \pm 4.40$ & -2.56 & 0.11 \\
\hline $20 \mathrm{MIN}$ & $73.53 \pm 4.70$ & -2.60 & 0.11 \\
\hline $30 \mathrm{MIN}$ & $74.20 \pm 4.67$ & -1.72 & 0.29 \\
\hline $60 \mathrm{MIN}$ & $73.67 \pm 4.17$ & -2.43 & 0.12 \\
\hline $120 \mathrm{MIN}$ & $73.30 \pm 4.48$ & -2.91 & 0.07 \\
\hline $180 \mathrm{MIN}$ & $78.29 \pm 5.53$ & 3.69 & 0.09 \\
\hline
\end{tabular}

There was significant increase in DBP at $1 \mathrm{~min}$ in Sevoflurane group. Thereafter, there was no significant change in SBP from baseline in the study period.

\section{CHANGES IN MEAN DBP}

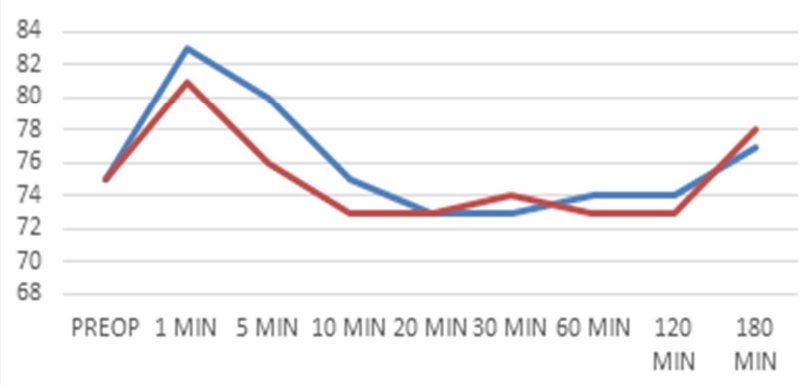

-DBP MEAN ISOFLURANE D DBP MEAN SEVOFLURANE

Figure 3: Changes in mean diastolic blood pressure after administration of isoflurane and sevoflurane

On intergroup comparison, there was no statistically significant difference in DBP in the study period of 180 minutes except the DBP in Sevoflurane group was significantly lower than Isoflurane group at 5minutes.

\section{MEAN RECOVERYTIME}

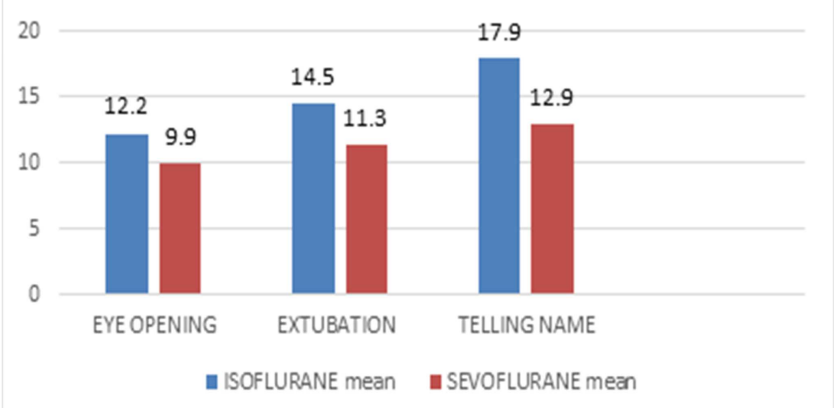

Figure 4: Mean Recovery Time in Patients Receiving Isoflurane and Sevoflurane

Mean recovery time was significantly earlier $(\mathrm{p}<0.001 \mathrm{HS})$ in Sevoflurane group than Isoflurane group.

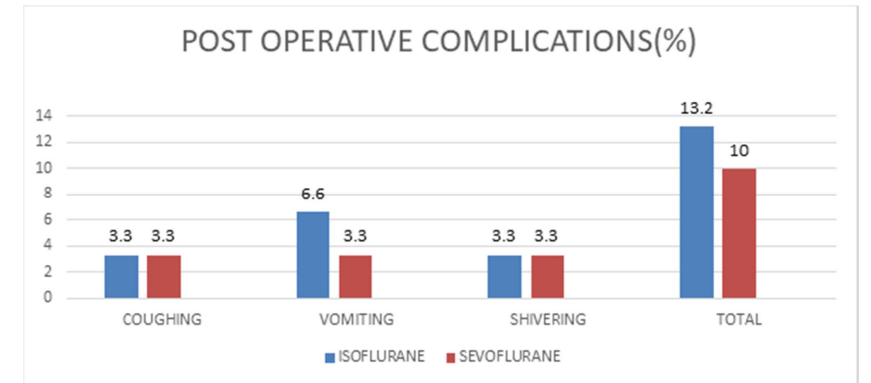

Figure 5: Post-Operative Complications in Patients Receiving Isoflurane and Sevoflurane

Post-operative complications were minimal and almost comparable in both the groups.

\section{Discussion}

Neurosurgery is a challenging field for anaesthesiologists, related to altered physiology caused by neurosurgical disease. Disease and injury may interfere with the control of cerebral circulation and thus predispose to cerebral ischemia and cerebral damage. Anaesthetic drugs have powerful effects on brain. The alterations they produce in cerebral circulation can be used to ensure good operating conditions to neurosurgical patients and to limit any neuronal damage. The choice of anaesthetic drugs should provide good intracranial operating conditions. There are many facets to this includings: a) maintaining adequate cerebral perfusion pressure. b) Avoiding factors causing increased ICP like hypoxia, hypercarbia, vasodialating drugs, cerebral venous obstruction, incomplete depth of anaesthesia. C) Reducing brain bulk. D) Protecting against the sudden development of cerebral ischemia. E) at end of the surgery a rapid recovery of consciousness is essential so that early neurological assessment can be done. An ideal anaesthetic agent should be non-inflammable, rapid induction and rapid recovery, odourless, non-irritant, minimal cardiovascular and respiratory effects, no adverse drug interaction, no organ toxicity, ease of administration, minimal metabolism in body.

Sevoflurane has several characteristics of an ideal neuroanaesthetic agent like low blood gas solubility, ${ }^{[6]}$ haemodynamic stability, non-pungent, minimal airway irritation. Sevoflurane has CNS effects like decrease cerebral metabolic rate of oxygen, maintains cerebral blood flow, little or no effects on intracranial pressure, no evidence of seizure activity. It has less than 5\% metabolized and potentiates muscle relaxant. Haemodynamics should be stable and variations should be minimal when neurosurgery is concerned. For a long time isoflurane was considered to be the agent of choice of inhalational anaesthetic agent in neuroanaesthesia. In neurosurgery cases early recovery is critical to obtain early neurological assessment in the postoperative period. The new inhalational agents discovered allow a rapid, pleasant induction and stable hemodynamics and rapid recovery with minimal hangover effects. Investigations suggest that Sevoflurane maintains anaesthesia safely without disturbances of the cardiovascular system and its low solubility may provide more rapid emergence from anaesthesia. With the background of these principles of 
neuroanaesthesia, we planned a prospective, randomized study "Comparison of hemodynamic and recovery characteristics of isoflurane and sevoflurane in neuroanaesthesia patients."

\section{Heart rate}

In our study, there was statistically significant increase in pulse rate from 1 minute to $180 \mathrm{~min}$ in Isoflurane group. There was statistically significant increase in pulse rate at 1 min in Sevoflurane group and thereafter there was no significant difference in pulse rate than baseline after $5 \mathrm{~min}$ till $180 \mathrm{~min}$. But the increase was less than $20 \%$ of the basal pulse rate in Isoflurane and Sevoflurane group. On intergroup comparison, the pulse rate at 20 minutes to 120 minutes was significantly less in Sevoflurane group than Isoflurane group $(\mathrm{p}<0.05)$. Implying that there was no clinically significant change in heart rate after Isoflurane and Sevoflurane administration in any of the group. Tachycardia occurring with Isoflurane anaesthesia may be due to increased beta activity or baroreceptor mediated reflex invoked by hypotension. This may be better preserved in Isoflurane anaesthesia than with Sevoflurane, tachycardia increase myocardial oxygen demand and reduced blood supply time. Edward J. et al, ${ }^{[7]}$ found that heart rate was faster after incision in patients of Isoflurane. Holaday et al, ${ }^{[5]}$ in his evaluation of clinical characteristics of Sevoflurane found that it did not produce tachycardia. Malan T. Philip et al, ${ }^{[8]}$ evaluated the hemodynamic effects of sevoflurane at 2.0 MAC in human volunteers not undergoing surgery comparing with Isoflurane at 1.5-2 MAC, found rise in pulse rate in Isoflurane group. C.L.Chiu et al, ${ }^{[9]}$ compared maintainace and recovery characteristics of Sevoflurane and Isoflurane anaesthesia in sixty Malaysian patients undergoing breast lump excision. The rise in systolic blood pressure was significantly more in Isoflurane group than Sevoflurane group. There was no significant difference in pulse rate changes in both the groups. In our study, heart rate was significantly more in Isoflurane group at 20,30, 60 and 120 minutes than in Sevoflurane group. Since the above study was of shorter duration less than 20 min this variation might have occurred. During Isoflurane anaesthesia, tachycardia may be better controlled with the intermittent use of narcotics which is not used in our study. Sohrab negarkar etal (2014), ${ }^{[10]}$ observed that the mean heart rate was more in Isoflurane group than Sevoflurane group at $25 \min (\mathrm{p}>0.05)$. However, the mean heart rate was comparable between the two groups during the study period. Deepak singh etal $(2009),{ }^{[11]}$ observed that there was no significant change in heart rate at any point of time in Sevoflurane and Isoflurane group intra-operatively

\section{Systolic blood pressure (SBP) and Diastolic blood pressure (DBP) \\ In our study, there was statistically significant increase in $\mathrm{SBP}$ and DBP at $1 \mathrm{~min}$ and $5 \mathrm{~min}$ in Isoflurane group. There was statistically significant increase in SBP and DBP at 1 min in Sevoflurane group ( $p<0.05$ ). But the increase was less than $20 \%$ of the basal SBP and DBP. On intergroup comparison, the SBP and DBP at 5 minutes was less in Sevoflurane group than Isoflurane group. Implying that, there was no clinically significant change in SBP and DBP}

after Isoflurane and Sevoflurane administration in any of the group. Edward J. et al, ${ }^{[7]}$ compared blood pressure and heart rate changes in healthy patients duing anaesthesia with Sevoflurane and Isoflurane along with rate of recovery after anaesthesia. Anaesthesia was maintained with approximately 1MAC (Sevoflurane 2.05\%; Isoflurane 1.15\%). They found that, SBP and DBP were well maintained in Sevoflurane and Isoflurane group patients. Wallin et $a{ }^{2},{ }^{[2]}$ found that cardiovascular variables were well maintained with Sevoflurane. Malan T. Philip et al, ${ }^{[8]}$ evaluated the haemodynamic effects of Sevoflurane in 21 healthy volunteers not undergoing surgery comparing with Isoflurane. They found that sevoflurane did not alter heart rate, decreased mean arterial pressure with no adverse cardiovascular properties. The cardiovascular effects of Sevoflurane were similar to those of Isoflurane. Deepak singh et al (2009), ${ }^{[11]}$ concluded that none of the patients demonstrated any haemodynamic instability that required use of rescue drug in Sevoflurane or Isoflurane group. Sohrab negarkar et al $(2014),{ }^{[10]}$ observed that there was increase in SBP in Isoflurane group at $10 \mathrm{~min}, 15 \mathrm{~min}$ and 30 min than Sevoflurane group which was statistically significant. There was increase in DBP in Isoflurane group at $10 \mathrm{~min}$ and $30 \mathrm{~min}$ than Sevoflurane group which was statistically significant. There was statistically significant increase in mean arterial pressure in Isoflurane group at 10 $\mathrm{min}, 20 \mathrm{~min}$ and $30 \mathrm{~min}$ than Sevoflurane group. They concluded that the differences were clinically not significant as none of the patient in either group required vasopressor support. Ayman A. Ghoneim et al (2015), ${ }^{[12]}$ observed that in Isoflurane, Sevoflurane and Desflurane groups showed significant decrease in mean arterial pressure but it was within acceptable limit (within 10\% from baseline) and did not require any ephedrine or fluid bolus. The patients were haemodynamically stable in all three groups.

\section{Recovery from anaesthesia}

In our study, the mean recovery time was faster in Sevoflurane than in Isoflurane after switching off the inhalational agent, the emergence time was $12.23 \pm 2.20$ minutes and $9.96 \pm 1.67$ minutes in Isoflurane and Sevoflurane group respectively. The blood -gas solubility coefficient of Sevoflurane is lower than Isoflurane. This property of sevoflurane should allow a more rapid induction of anaesthesia and emergence as compared to other inhalational anaesthetic agent. Anaesthesia induction time was not evaluated in our study. Saito et al, ${ }^{[13]}$ have confirmed that anaesthetic induction with Sevoflurane is more rapid than with other currently inhaled anaesthetics such as Enflurane, but found emergence from Sevoflurane anaesthesia to be no more rapid than emergence from Enflurane anaesthesia. Cantillo et $\mathrm{al}^{[14]}$ had shown the magnitude of the differences between the two groups for most recovery end points was greater than what was reported for anaesthesia of shorter duration. But may be our study was of long duration, the magnitude of the differences between two groups were shorter. Alain Gauther et al, ${ }^{[15]}$ in his study shown that the low solubility anaesthetic Sevoflurane provides faster recovery than Isoflurane for patients undergoing long duration neurological surgery. Sevoflurane also allowed for a faster basic neurological examination than 

0

Isoflurane. Edward Frink et al, ${ }^{[7]}$ showed that emergence from Sevoflurane -02 anaesthesia could be expected in less than half the time taken after discontinuation of Isoflurane o2 anaesthesia $(7.5 \pm 0.5$ versus $18.6 \pm 2.0 \mathrm{~min})$. It is possible that our results, though still significant, show a smaller difference $(9.96 \pm 1,67$ versus $12.23 \pm 2.20 \mathrm{~min})$ in emergence time between these two volatile agents because of the compounding influence of nitrous oxide elimination. Average surgical times in our subjects were of sufficient duration to permit the relatively slow process of $\mathrm{N} 2 \mathrm{O}$ equilibrium with vessel-poor tissues, thus creating large tissue stores. Ayman A. Ghoneim et al (2015), ${ }^{[12]}$ observed that mean emergence time (time to tell name, eye opening) and extubation time were significantly shorter in Sevoflurane and Desflurane than Isoflurane group. Deepak singh et al (2009), ${ }^{[11]}$ observed that tracheal extubation and emergence occurred significantly earlier in Sevoflurane group than Isoflurane group enabling early neurological assessment. Sean R. Bennet et al (2001), ${ }^{[16]}$ observed that eye opening and extubation were earlier in Sevoflurane group than Isoflurane group in valvular heart surgery patients.

\section{Postoperative Complications}

Our results showed that, the incidence of coughing was equal in both groups $(3.33 \%)$ in the immediate postoperative period. The incidence of shivering was equal in both the groups $(3.33 \%)$. The incidence of vomiting was more in Isoflurane group $(6.66 \%)$ than Sevoflurane group $(3.33 \%)$. Vomiting is distressing and disadvantageous postoperatively specially in neurosurgery as it can lead to increase in ICP which may affect postoperative neurological outcome. The patients were administered inj. Ondansetron $4 \mathrm{mg}$ and inj. Dexamethasone intravenously. Beverely Philip et al, ${ }^{[17]}$ observed lower incidence of nausea and vomiting in Sevoflurane group than Isoflurane group which may be due to shorter duration of exposure to the nauseating inhaled anaesthetic, because Sevoflurane was more rapidly eliminated from the body. Edward Frink et al, ${ }^{[7]}$ observed the incidences of post procedural nausea and vomiting were not different as also evident from our observations. Deepak Singh et al (2009), ${ }^{[11]}$ noted that 4 patients(10\%) in Sevoflurane and Isoflurane group had nausea and vomiting. Agitation was seen in 7 patients $(17.5 \%)$ in Sevoflurane group and 6 patients $(15 \%)$ in Isoflurane group. Opioids also contribute to vomiting and both groups received fentanyl. As well as the surgical procedures themselves may stimulate vomiting. Another post-operative adverse experience, cough, was reported after both anaesthetic regimens. All patients were intubated and this represented cough at extubation.

\section{Conclusion}

Sevoflurane is better inhalational agent than Isoflurane in neuroanaesthesia as it provides stable haemodynamics during maintainance of anaesthesia and rapid recovery allowing faster postoperative basic neurological examination after neurosurgery.

\section{References}

1. William Dolan M, Stevens WC, Eger El II, Cromwell TH, Halsey MJ, Shakespear TH, Miller RD. The cardiorespiratory and respiratory effects of isoflurane-nitrous oxide anaesthesia. Canadian Anaesth Society Journal 1974;21: 557-567.

2. Wallins RF, Regan BM, Napoli MD, Stem IJ. Sevoflurane: a new inhalational anaesthetic agent. Anesth Analg 1975; 54:758-66.

3. Manohar et al. Porcine systemic organ blood flow 1.0 and 1.5 MAC sevoflurane with or without nitrous oxide. J Pharmacol Exp Ther 1984; 231:640-48.

4. Bernard JM, Wouters PF, Doursout MF, Florence B, Chelly JE, Merin RG. Effects of sevoflurane and isoflurane on cardiac and coronary dynamics in chronically instrumented dogs. Anesthesiology 1990; 72:659-62.

5. Holaday DA, Smith FR. Clinical characteristics and biotransformation of sevoflurane in healthy human volunteers. Anesthesiology 1981;54:100-6.

6. Schwender D, Daunderer M: Sevoflurane and the nervous system. Anesthetist 1998 nov; 47( suppl 1): S37-42.

7. Edward Frink JJr, Malan TP, Atlas M, Dominguez LM, Di-Nardo JA, Brown BR Jr. Clinical comparison of sevoflurane and isoflurane in healthy patients. Anaesth Analg 1992;74:241-5.

8. Malan TP, et al : Cardiovascular effects of sevoflurane compared with those of isoflurane in volunteers. Anaesthesiology 1995 nov;83(5):918-28.

9. Chiu CL, Chan YK, Ong GS, Dellican AEA. Comparison of the maintenance and recovery characteristics of sevoflurane-nitrous oxide against isoflurane-ntrous oxide anesthesia. Singapore Med J. 2000nov; 41(11):530-3.

10. Sohrab N, Ali Peirovifer, Ata M, Masod P, Samad EG, Haniye M, Soheil N. HHaemodynamic parameters of low flow isoflurane and low -flow sevoflurane anesthesia during controlled ventilation with laryngeal mask airway. Anesth Pain Med 2014 Dec ; 4(5):e20326.

11. Deepak Singh, Girija PR, Hari HD, Parmod KB. Sevoflurane provides better recovery as compared with isoflurane in children undergoing spinal surgery. Neurosurg Anesthesiol 2009july ; 21(3):202-206.

12. Ayman AG, Magda SA, Hossam ZG, Mohammed A. awakening properties of isoflurane, sevoflurane and desflurane in paediatric patients after craniotomy for supratentorial tumours. J Neurosurg Anesthesiol 2015 jan; 27(1):1-6.

13. Saito S, Goto F, Kadoi $\mathrm{Y}$, Takahashi T, Fugita $\mathrm{T}$ and Mogi $\mathrm{K}$ : Comparative clinical study of induction and emergence time in sevoflurane and enflurane anesthesia. Acta Anaesthesiol Scand 1989; 33:389-90.

14. Cantillo J, Goldberg ME, Larijani GE etal. Recovery parameters after sevoflurane and isoflurane anaesthesia. Pharmacotherapy 1997; 17:779-82.

15. Gauthier Alan. Sevoflurane provides fester recovery and postoperative neurological assessment than isoflurane in long duration neurosurgical cases. Anesth Analg2002 nov; 95(5):1384-8.

16. Sean R. Bennet, Steve CG. Sevoflurane versus Isoflurane in patients undergoing valvular cardiac surgery. J of Cardiothoracic and Vascular Anaesthesia April 2001;15(2):175-178.

17. Beverelly Philip BK, Kallar SK, Bogetz MS etal. A multicentre comparison of maintainance and recovery with sevoflurane or isoflurane anaesthesia: the sevoflurane multicentre ambulatory group. Anesth Analg 1996;83:314-9.

18. Schwender D, Daunderer M. Sevoflurane and the nervous system. Anesthetist 1998 nov; 47 suppl 1: S37-42.

19. Katoh T, Suguro Y, Nakajima R, Kazama T, Ikeda K. Blood concentrations of sevoflurane and isoflurane on recovery from anaesthesia. Br. J Anaesth 1992;69:259-62.

20. Brothwick FM, Fitch W. Anaesthesia for the neurosurgical patient in clinical anaesthesia 1st edition, 1996, Churchill Livingstone, Aitkenhead AR and Jones RM, chapter 12, p-513-531. 
0

Copyright: (c) the author(s), publisher. Academia Anesthesiologica International is an Official Publication of "Society for Health Care \& Research Development". It is an open-access article distributed under the terms of the Creative Commons Attribution Non-Commercial License, which permits unrestricted non-commercial use, distribution, and reproduction in any medium, provided the original work is properly cited.

How to cite this article: Vali LF, Khobragade SM. Comparative Study of Maintenance and Recovery Characteristics of Sevoflurane and Isoflurane in Neurosurgery. Acad. Anesthesiol. Int. 2019;4(2):106-112.

DOI: dx.doi.org/10.21276/aan.2019.4.2.26

Source of Support: Nil, Conflict of Interest: None declared. 